\title{
TANITMA 3: Geçmiş ve gelecek zaman arasında şekillenen bir İstanbul bilim kurgu eseri: Osmanlı Cadisı
}

Sevnur KORKUT'

Zamanı verimli ve etkin kullanma konusunda günlük hayatta yardımcımız olan kitapların zihnimizi geliştirme, üretkenliğimizi arttırma gibi işlevleri vardır. Yaşanan ve ileride yaşanacak olan durumları çözümleme konusunda kitapseverlere fikir vererek farklı yolları da onlar için mümkün kılar. Çağın üretilen araçlarının çok ötesinde, yaşanılan dönemde henüz gerçekleşmeyen teknolojik araç ve gereçlerin olduğu bir eseri okumak, okurun düşünce dünyasını genişletirken merak duygusunu da arttırır. Bilim kurgu eserleri de okuyucu için bu yönde katkı sağlar ve zihnimizde daha önce oluşturmadığımız bir mekân algısı yaratır.

"Bilim kurgu türündeki romanlar Osmanlı Devleti’nin son dönemlerinden beri edebiyatımızda zaman zaman örneklerine rastladığımız eserler olarak karşımıza çıkar.” (Uyanık, 2013). Batı edebiyatından alınan roman türü Tanzimat ile edebiyatımıza girmeye başlarken Jules Verne'nin bilim kurgu

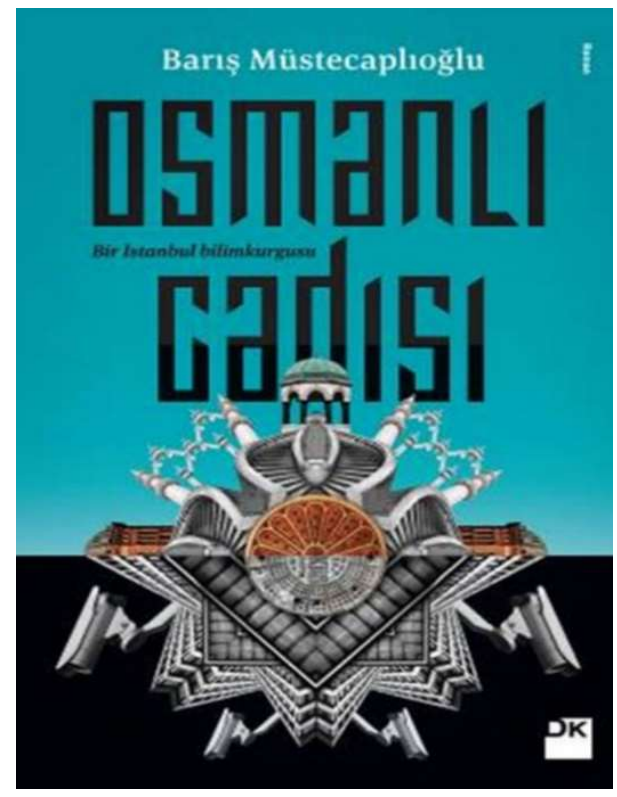
türündeki eserleri gazetelerde tefrika edilmeye başlanır ve yoğun ilgi ile karşılanır. Batı dünyasında "science-fiction" olarak bilinen bu türün isim babası Türkçede Orhan Duru'dur. "Bilim kurgu" isminin yaratıcısı Orhan Duru "Belki çok kişi tarafindan bilinmiyor ama 'bilim kurgu' adının babası benim" (akt. Çelikel, 1996: 18) diyerek bugün hâlâ kullandığımız bir kelimenin varlığını ortaya çıkarmıştır. "Duru, 1 Ocak 1973 tarihinde Türk Dili dergisinin 256. sayısında hazırladığı bilim kurgu dosyasında bu ismi önerir ve kabul görür.” (Reyhanoğulları, 2012: 2184). Birçok tanımının yapıldığı bilim kurgunun Orhan Duru tarafından kabul edilen tanımını ise Michel Butor yapmıştır: "Bilim kurgu, bilimin izin verdiği oranda mümkün olabilecek olanı kullanan bir yazındır, gerçeklikle sınırlandırılmış bir düşçülüktür” (akt. Duru, 1973: 334).

Üretimi henüz yapılmayan araçları, robotları, farklı mekânları kitaplarda bulmak, var olan nesnelere karşı bakış açımızı değiştirir ve ufkumuzu genişletir. Günümüzde teknolojinin ilerlemesi hatta daha da ilerleyecek olması doğanın düzenine dolaylı ya da doğrudan bir müdahalenin varlı̆̆ını ortaya koyar. "Küresel ısınma, denizlerin kirlenmesi, çölleşme, erozyon, nüfus artışı, açlık tehdidinin pek çok ülkede varlığını sürdürmesi, kaynak paylaşımı gibi sorunlar; modern toplumda çevre politikalarının başarısızlığının kanıtıdır.” (Kılıç, 2006:109). Modern toplum, çevre politikalarında teknolojinin yardımı ile geliştikçe bir yandan saydığımız tehditler de giderek artmaktadır. Şu an dahi evrenin düzenini değiştirmeye yetebilecek bilimsel bilgi insanlığın elinde mevcutken ilerleyen zamanlarda bu bilgilerin kullanımının doğa için yararı ya da zararı ne derece olabilir? Yeşilin kaybolduğu, sınıf farkının iyice belirginleştiği hatta mekân kavramının bu farkı kırmızı çizgilerle çizdiği bir yerde insanların var olması, tutumları nasıl olabilir? Barış Müstecaplıoğlu'nun 2016 yllında Doğan Kitap’tan çıkan bilim kurgu türündeki Osmanlı Cadısı adlı eserinde okur, iki farklı dünyaya tanıklık ederken bu soruların cevaplarını

1 YL Öğrencisi, Siirt Üniversitesi, Sosyal Bilimler Enstitüsü, Türkçe Eğitimi Programı (Siirt, Türkiye), sevnurkorkut@gmail.com, ORCID ID: 0000-0001-7144-8652 [Makale kaylt tarihi: 20.12.2019-kabul tarihi: 20.03.220; DOI: $10.29000 /$ rumelide.706557] 
da kitapta bulmaktadır. Kitap, yirmi üç bölümden oluşur. Yazarın "íki farkhı çağda geçen öyküleri tek romanda birleştirdim.” ifadesinden hareketle kitabın olay akışının iki farklı dönem üzerinde kurgulandığını görmekteyiz. Müstecaplığlu, iki farklı dönemi yazmasının sebebini "Okura bir zaman yolculuğu keyfi yaşatmak istedim.”2 sözleriyle ifade eder. Müstecaplığlu, aynı zamanda bilim kurgu türünün insanın hayal dünyasını geliştirdiğini şöyle belirtir: "Hayalî bir diyar yaratmak için gerçek dünyayı iyi tanımak gerekiyor, çünkü hayal gücümüz de gerçek dünyadan besleniyor. Gerçek dünyanın coğrafyasın, haritasındaki tarihsel değişimleri, tarihini, mitlerini, hayvanlarmı, bitki örtüsünü iyi tanımahsını ki enteresan detaylar yakalayıp bunlar hayalinizde fantastik bir şekle sokabilesiniz" (akt. Yüksel, 2014: 17).

Kurguda sık sık kullanılan geriye dönüş tekniği, kurgunun akıcı şekilde yansıtılmasını sağlamıştır. Kimi zaman Osmanlı Dönemi’nde Kaptan Haymanalı Süleyman Paşa'nın Şahmeran adlı gemisinin batmasına tanıklık ederiz, kimi zaman da teknolojinin ilerlediği Megakulelerde yaşanan gri hayata. Bir potada eritilen iki farklı öykünün kitabın sonunda yeni bir hikâye ile birleştirilmesi kitabın kurgusunu güçlendirmiştir. Son bölümde okur, yazarın sağlam bir şekilde oluşturduğu kurgunun gerçek hayata uzak olmayan iletilerini yani doğanın yok edilişini iyi değerlendirmelidir.

Osmanlı Dönemi’nde Kaptan Haymanalı Süleyman Paşa’nın Şahmeran adlı kalyonunun batması ve batış sebebi kitabın ilk bölümünde karşımıza çıkar. Kalyonun batış sebebi olarak gösterilen ve iblis olarak tarif edilen bir kız vardır. İlerleyen sayfalarda iblis olamayacak kadar da güzel olduğu, herkesi güzelliği ile büyülediği belirtilir. Haymanalı Süleyman Paşa, kızın ırzına geçtiği için fırtına ile cezalandırıldıklarını düşünür. Davranışlarımızın sonuçlarını inkâr etmenin faydasızlığı, sonuçlar ne olursa olsun yapılanların üstlenilmesi gerektiği mesajı okura verilir. Haymanalı Süleyman Paşa yaptığından pişmandır. Tövbe edip firtınadan kurtulduktan sonra canı pahasına bu kızı korumaya ant içer. Romanın Osmanlı Dönemi’nde geçen bölümlerinde; Haymanalı'nın firtınada bulduğu kıza Ayşe adını vermesini, onu Mevlevilere emanet etmesini, onlarla yoldaş olmasını, Haymanalı'dan hamile kalan Ayşe'nin daha sonra nasıl kimsesiz kaldığını ve kendisini koruyan Mevlevilerin dostu Halil Efe'nin çetesi içerisinde yaşamını devam ettirmesini okuruz. Ayşe'nin insanlar ve doğa üzerinde büyülü güçlerini kullanması, kitabın isminde yer alan cadı kelimesini karşılasa da eserin bilim kurgu bir eser olduğunu yansıtmada yazar kabiliyetli bir tavır sergilemiştir. Yazar, eserin bilim kurgu türünde olduğunu, İstanbul Cumhuriyeti’nde anlattığı son model teknolojik araçlar ile pekiştirir. Osmanlı Dönemi'nde geçen bölümlerde Ayşe, cadı olarak tanımlansa da teknolojinin ilerlediği bölümlerde, eserin bilim kurgu yönünü yansıtan yapısal ve kurgusal içeriklerine sadık kalan yazarın, olayları bağlama ve çözüme ulaştırma konusunda türün özelliklerinden uzaklaşmadığı görülür. Kitabın Osmanlı Dönemi’ni anlatan bölümlerinde orman, toprak, deniz gibi henüz bozulmamış bir doğa tasviri vardır. Bu doğa tasvirinin yapılması okuyucuya karşılaştırma imkânı sunar. Megakulelerin, helimobil yani uçan araçların anlatıldığı teknolojinin geliştiği zaman dilimindeki doğa ile eski zamanların doğası karşılaştırılır.

Kitabın sonunda farkına varacağımız ve belki de dehşete düşeceğimiz, düğümün çözümlenen bölümünde doğa için endişelerimiz artacaktır. Kurgunun her ne kadar gelecek ve geçmiş arasında oluştuğunu görsek de çözüm bölümünde kitap, aslında tek bir zaman diliminde yaşananlara odaklanmıştır. İşte dehşete düşeceğimiz bölüm de burasıdır. Endişeleneceğimiz noktayı Türk edebiyatının usta hikâyecisi Sait Faik’in Son Kuşlar adlı öyküsünde de görmekteyiz. Teknoloji ilerlese de insanın temel gereksinimlerinden biri olarak koruması gereken doğaya karşı bakış açısı 1950’lerde de ilerleyen teknolojik zaman diliminde de aslında aynıdır. Okurun, kitabın sonunda hissedeceği aynı 
korkuyu, aynı endişeyi Sait Faik de Son Kuşlar adlı öyküsünde Mühendis Ahmet Bey’in yol kenarındaki çimenleri söktürmesi üzerine hisseder:

\begin{abstract}
"Kuşları boğdular, çimenleri söktüler, yollar çamur içinde kaldı. Dünya değişiyor dostlarım. Günün birinde gökyüzünde, güz mevsiminde artık esmer lekeler göremeyeceksiniz. Günün birinde yol kenarlarında, toprak anamızın koyu yeşil saçlarını da göremeyeceksiniz. Bizim için değil ama çocuklar, sizin için kötü olacak. Biz kuşları ve yeşillikleri çok gördük. Sizin için kötü olacak. Benden hikâyesi" (Abasiyanık, 2019: 7).
\end{abstract}

Müstecaphığlu, kitabındaki gelecek tahminlerini şu an için belki hayal ürünü olan fakat ilerisi için gerçekleşmesi çok da zor olmayan bir yapı etrafında kurgular. Gelecek zamanda, teknolojinin geliştiği çağlarda yok olmuş doğal yaşam ve güzellikleri; geçmiş zamanda -Osmanlı Dönemi’nde- aktardığı doğal güzellikler ile eş zamanlı sunarak okurun karşılaştırma yapmasını sağlamıştır. Süreç içerisinde olabilecek acı tabloyu gözler önüne sererek farkındalık oluşturmayı başarmıştır. Teknolojinin geliştiği, İstanbul Şehir Cumhuriyeti’nin kurulduğu, yeryüzeyindekiler ile Megakulelerde yaşayanlar arasında sınıfsal bir farklılığın olduğu, insanların mavi gökyüzünü, yemyeşil doğayı unuttuğu hatta hiç bilmediği bir zaman dilimini okuruz. Bu zaman diliminde yaşayan özel dedektif Kemal, Megakulelerde lüks bir hayat sürmektedir. Üçüncü bölümde Kemal'in, yok olmuş doğal güzellikleri simülasyon üzerinden izleyerek var olduğu çağa katlanmaya çalıştığını öğreniriz. Anlatıcının, doğanın insan için önemini vurgulayan bakış açısı ve tutumu Kemal karakteri üzerinden yansıtılır. Kemal'in nostaljiye sahip eşyalara düşkün olduğunu, var olan zamana aykırı bir örgüt -íSEH- içinde yer aldığını, düzeni değiştirmek için bir zamanlar devlete aykırı hareket eden bu toplulukla birlikte olduğunu öğreniriz. Bu topluluk içinde yer alan Neşe adında bir kadına aşık olduktan sonra mecburen buradan ayrılmak zorunda kalmıştır. Özel dedektiflik yaparak zengin müşterileri sayesinde o da yeryüzeyinde değil Megakulelerde yaşamaya başlar. Küme baş ağrısı denilen, tedavisi olmayan bir hastalığı vardır. Kemal'in çok yakın dostu Okyanus, teknoloji ile içli dışlıdır. Evi olarak bildiği deposundan hiç çıkmayarak robot üretmeye çalışır. Okyanus; yalnızlaşmış ve dünyasına sayılı insan alan bir kişiliktir. Kitapta Kemal ve Okyanus arasında geçen dostluk ilişkisi son bölümde de kendini gösterir. İkinci bölümde robotların ve insan polislerin çözmeye çalıştığı soruşturmada üç kişilik bir ailenin katledildiğini öğreniriz. Tehlikeli durumlarda insan polislerin ölme riskine karşlık, gelişen teknoloji artık robotları devreye sokmuştur. Böylece insan polisler, tehlikeye girmek zorunda kalmaz. Elmas Sağlık Hizmetleri’nin kurucusu Gül Hanım, üç kişilik ailenin neden katledildiğini Kemal'in çözmesini ister. Yeraltı örgütü olan İSEH’in cinayetle bağlantısı olup olmadığını araştırmasını, bu işi kabul ettiği takdirde tedavisi yok diye bilinen küme baş ağrılarının ameliyatını yapacağını vadeder. Kemal’i geçici olarak iğnelerle tedavi eden Gül Hanım; insanların hırslarının, kendileri için her yolu denemeye kararlı, bencil duygularının yansımasıdır. Kemal, küme baş ağrılarına artık dayanamadığı için işi kabul eder. İlerleyen teknolojik gelişmelerin anlatıldığı bölümlerde bir tarafta yemyeşil doğanın varlığını dahi bilmeyen, refah düzeyi yüksek Megakulelerdeki insanlar ve yeryüzeyine sıkışmış, kalabalıklar içinde yaşamaya çalışan insanlar vardır. Bir tarafta ise doğanın geçmiş zamanlardaki varlığını bilen ve ona yasa dışı uygulamalar ile de olsa ulaşmaya çalışan insanlar vardır. Kitap, sürükleyiciliğini iki zaman dilimini de merak uyandırıcı olaylar etrafında oluşturduğu kurgusuyla kazanır.

Kitabın 17.bölümünden itibaren Ayşe'nin nereden geldiği ve nasıl bir yaşama sahip olduğu anlatılır. Dünyadaki insanlar tarafından çok beğenilen Ayşe, aslında gelmiş olduğu Mafron adındaki gezegende herkesin kendisi gibi olduğunu "Benim ülkemde herkes güzeldi. (...) Sizin yanınızda böyle ilgi görmek beni yoruyor.” (Müstecaplığlu, 2019:196) ifadeleriyle aktarır. Bu bölümde Ayșe ile ilgili daha net bilgiler öğrenmeye başlarız. Osmanlı Dönemi’nde Halil Efe'nin çetesinin gözcülerinden olan Bahtiyar’a gezegenindeki olayları anlatmaya devam eder: "Hiçbirimiz büyücü değildik. (...) Zihinden konuşmak, 
dokunmadan eşyayı hareket ettirmek, yabancı bir lisanı birkaç haftada öğrenebilmek, bunlar kimseye zor gelmezdi... Siradan şeylerdi bizim için. (...) Bunları yapabilenlere cadı dediğinizi bilseler amma şaşırırlardı!” (Müstecaplığlu, 2019:196). Kitabın adındaki cadı ifadesi, Ayşe yani Mafron gezegenindeki adıyla PAZı19üün Osmanlı Dönemi’nde insanlar tarafından algılanan bakış açısından gelir. Mafron gezegenini Bahtiyar’a zihin akışı üzerinden gösterir.

Hiçbir ağacın ve bitkinin olmaması, her yerin parlak metal, cam ve taş binalarla dolu olması Bahtiyar'ı boğmaya başlar. Bunun üzerine Ayşe zihin akışını durdurur. Kalabalıklar, uçan araçlar, kulak tırmalayan uğultular, gri gökyüzü, yeşilliğe hasret yeryüzü soluk soluğa kalan Bahtiyar’ı daraltır (Müstecaplığlu, 2019:199-200). Zihin akışı durdurulduğunda Bahtiyar kendi ülkesinin doğasına şükreder. O gezegende çocukların olmayışı da dikkatini çeker. 18. bölümde Ayşe'nin yani PAZı194'ün Mafron'dan neden ve nasıl ayrıldığı detaylı şekilde verilir. Mafron gezegenindeki insanların zamansız olmasının getirdiği sonuçlar bu bölümde değerler üzerinden anlatılır: "Zamansız olmak fanilerin ruhunu kirletiyordu, kaybedilecek şey kısa bir ömür değil, ebediyet olunca, çoğu insan hayatta kalabilmek adına tüm değerlerinden vazgeçiyordu” (Müstecaphoğlu, 2019:225).

İki zamanda işlenen, birbirinden kopuk gibi görünen olaylar 20. bölümde birleşir ve çözüme ulaşır. İki hikâye de 23.bölümde kitabın üçüncü hikâyesi olarak nitelendireceğimiz kısımda birleştirilir. Toplumsal hafızanın önemi, teknolojinin dünyanın doğal akışını bozmadan önceki görüntüleri bu bölümdeki hikâye üzerinden verilir. Bilinçsiz kullanılan teknolojinin doğa üzerindeki çirkin sonuçları kitabın iletisini daha da anlamlı hâle getirir. Yaşamımızdaki teknolojinin sonuçları, bize geri dönüşü, doğanın yıpratılması düşündürücüdür. "Uygulamaya konan pek çok teknolojinin doğaya nasıl bir yük getirebileceği tam olarak kestirilememiştir.” (Kılıç, 2006:119). Son bölümde insanın doğadan uzaklaşmasını, bilimsel gelişmeler ile teknoloji gelişirken bilinçsiz bir tutumla hareket eden insanlığın neleri kaybedeceğini okuruz.

Robotların, uçan arabaların, Megakulelerin, neredeyse ölümsüzlüğü bulmaya yaklaşmış son moda sağlık hizmetlerinin yaygınlaştığı bir toplumun kaybediş hikâyesi anlatılır. Hafızası olmayan bir toplum üzerinden, yitirilen güzelliklerin acı tablosunun işlendiğini görmekteyiz. Madde odaklı bakışın kültürel, ekonomik, sağlık, insani değerlere yansıyışı ve doğanın yok oluşu başarılı bir olay akışı içerisinde verilir. Toplum hafızasının silinmesinin sonuçları ise yine insanların refaha kavuşamaması, ortak bir kültürde, yaşayışta buluşamaması üzerinden resmedilir.

Zaman değişimleri, toplumsal yapının değişip sınıf farkının belirginleşmesi, doğadan uzak bir yaşamın hissettirdikleri, tarihin çarpıtılması, toplumsal hafizanın yitirilmesi eserin iletisini anlamlı kılar. Her bölümün kurgusu sağlam bir şekilde oluşturulduğu için kitabı okurken bölümlerin sayfa sayısı size de az gelecektir. Zihnimizde doğa ile ilgili bir farkındalık oluşturacak olan bu eser, elimizdeki zenginlikleri kaybetmeden onların değerini bilmeye çağırıyor.

\section{Kaynakça}

Abasıyanık, S. F. (2019). “Son Kuşlar”, İstanbul: Türkiye İş Bankası Kültür Yayınları.

Çelikel, P. (1996). “Öykü Bir Tutkudur”, Yeni Yüzyıl, s.18

Duru, O. (1973). "Science-Fiction Sözcüğüne Türkçe Bir Karşllı Arama Denemesi”, Türk Dili, S. 256, s.332-340.

Kılıç, S. (2006). "Modern Topluma Ekolojik Bir Yaklaşım", Kocaeli Üniversitesi Sosyal Bilimler Enstitüsü Dergisi (12) 2006 / $2:$ 108-127.

Müstecaplığlu, B. (2019). “Osmanlı Cadısı”, İstanbul: Doğan Kitap 
Reyhanoğulları, G. (2012). "Türk Edebiyatının İlk Bilim-Kurgu Öyküleri ve Orhan Duru”, Turkish Studies, s:2184, Ankara

Uyanık, S. (2013). “Osmanlı Bilim Kurgusu: Fenni Edebiyat”, İstanbul: İletişim Yayınları.

Yüksel, A. A. (Ocak 2014). "Röportaj-Barış Müstecaplığlu”, Gölge e-Dergi, S. 76, s. 15-22. 